
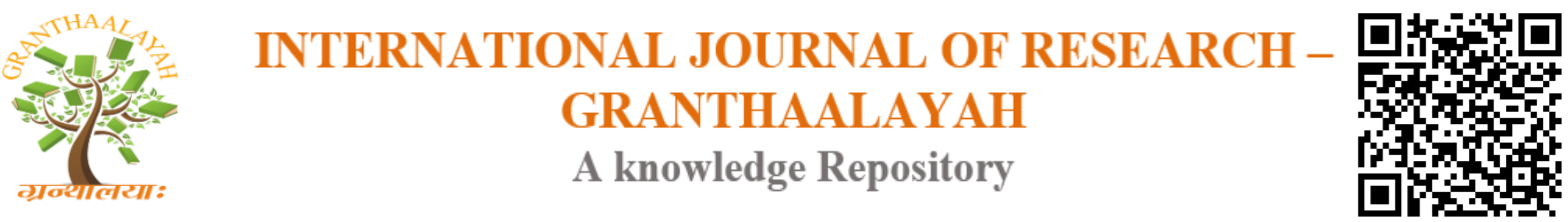

Science

\title{
SEM ANALYSIS AND STUDY OF MECHANICAL PROPERTIES OF UV AGED PVC/CORN COB COMPOSITES
}

\author{
Krisztina Roman ${ }^{* 1}$, Zita Szabo ${ }^{2}$, Bence Szeman ${ }^{3}$, Tamas Szabo ${ }^{4}$ \\ ${ }^{*} 1,4$ Institute of Ceramics and Polymer Engineering, University of Miskolc, Hungary \\ ${ }^{2}$ Institute of Petroleum and Natural Gas, University of Miskolc, Hungary \\ ${ }^{3}$ Institute of Geophysics and Geoinformatics, University of Miskolc, Hungary
}

\begin{abstract}
In this study, the aged mechanical properties and the modifier structure were determined. Biomaterials are often used as additives to plastics, in order to make the degradation easier in the environment. We examined the differences of the properties of samples differently aged; the ages of the samples were 1 and 3 years. The properties that were gathered from the mechanical tests, such as tensile-, flexural-, impact-, and hardness-test, show changes depending on the ages of the samples. Due to the aging, decrease of mechanical properties was experienced. The microcellular structures of the composites were studied by SEM analysis in order to understand the changes of the structures. It can be seen on the recording that the corn cob strengthens and sticks to the cells wall. The internal changes of the structure that were caused by the aging cannot be seen on the SEM micrographs.
\end{abstract}

Keywords: PVC; Corn Cob; Mechanical Properties; Aging; SEM.

Cite This Article: Krisztina Roman, Zita Szabo, Bence Szeman, and Tamas Szabo. (2018). "PREVALENCE OF LATENT TB INFECTION AMONG HEALTH CARE WORKERS, ALJAZEERA STATE TB CENTERS, SUDAN." International Journal of Research - Granthaalayah, 6(1), 347-353. https://doi.org/10.29121/granthaalayah.v6.i1.2018.1628.

\section{Introduction}

Over the last decade the use of bio-additives has become increasingly important. Mechanical parameters can be increased, by using bio additives. These bio materials modify the structure of the base matrix ${ }^{[1]}$. Therefore the composites can become biodegradable, environmentally friendly and less poisonous ${ }^{[2]}$. The main field of application of the composites is the construction industry, since these are easy to produce and are relatively cheap ${ }^{[3]}$.

Many of the rapidly developing countries have significant agricultural output. Farmers produce rice, sugar cane, corn and many other crops that can be used as bio-raw materials ${ }^{[4]}$. Many researchers have already investigated the applicability of biomaterials, it has been observed that bio additives strengthen the structure of the base matrix, and increase the resistance of the 
product to mechanical impacts. Researchers and manufacturers of plastic products work with these bio materials and try to convert expensive polymers or metals to environmentally friendly. The main reasons for the investigations are to reduce the costs and easily the transportation of the products.

The PVC (polyvinyl chloride) is a somewhat controversial material nowadays. The PVC is an extremely versatile material, but it has a very long biodegradation time, leading to some of the controversy around it. Many researchers have been trying to convert the structure of the PVC to be more biodegradable. Mixing bio additives into PVC base matrix could be a possible solution [5].

During our investigations we determined the morphology, the density and other properties of PVC / Corn cob composites and compared the results with the properties of neat PVC foams. The properties of the foams are highly dependent on the structure of the material (cell size, shape and cell wall thickness) and, of course, the density of the material ${ }^{[6]}$.

Polymers are sometimes subject to moderate or even high temperatures, ultraviolet rays, air or oxidants, and chemicals during their manufacture and the transportation, so these effects need to be simulated and tested ${ }^{[7]}$. The UV radiation causes molecular chain degradation. In the PVC / Corn cob composite, the corn cob changes the glass transition temperature and the clamping properties of the structure compared to the PVC foam. The following tests were performed on the test specimens:

- UV test $32,4 \mathrm{~W} / \mathrm{cm}^{2}$

- SEM analysis

- Hardness test

- Tensile test

- Bending test

- Impact test

\section{Materials and Methods}

\subsection{Materials}

For our investigations we used $\mathrm{K}=58 \mathrm{PVC}$ as base material. The natural blend beside the main ingredient contains lubricant, stabilizer, processing aids, foaming agent and corn cob filler. The compositions of the corn cob are generally: $42 \%$ cellulose, $46 \%$ hemicelluloses, $7 \%$ lignin and the remaining $5 \%$ additional organic substances ${ }^{[8]}$. The filler was added in a fiber form to the mixture. The corn cob was dried at $80{ }^{\circ} \mathrm{C}$ and then was made fibers from it. The average particle size was approximately $492 \mu \mathrm{m}$. The mixing ratio of PVC / Corn cob was 100/120 parts by weight. The density of the mixture was $1.1252 \mathrm{~g} / \mathrm{cm}^{3}$.

\subsection{Mixtures and Samples Preparation}

The PVC powder, the additives and the corn cob filler were homogenized in a high-speed mixer up to $110^{\circ} \mathrm{C}$. The final mixture was produced with a laboratory extruder. The parameters of the 
extruder were: screw $\mathrm{D}=30 \mathrm{~mm} ; \mathrm{L} / \mathrm{D}=20$ compression rate $1: 3$. The specimens were cut out of the extruded foam sheets by a pneumatic punching device.

\subsection{SEM}

The formed structure of the foam can be tested by using scanning electron microscope. The shape of the cellular structure and its size can be determined. The specimens must be prepared before the test. It is important that they must be electrically conductive, and they also have to tolerate vacuum and electron irradiation. If the specimen is made of insulating material, a thin conductive layer is required on the surface of the specimen. The surfaces of the specimens were plated with gold in order to create the required conductive layer. The type of the equipment that was used: ZEISS.

\subsection{UV Test}

The thermal stability of the PVC is poor without additives (stabilizer). The substance degrades during the processing and application. The major degradation processes of polymers are photooxidative, thermal, chemical, biological and mechanical degradations. Generally, these degradations occur simultaneously. A typical example for this is the effect of the sunlight. The $\mathrm{UV}$ radiation of the sunlight with the presence of $\mathrm{O}_{2}$ triggers the degradation of polymer molecules. At this time the molecular weight decreases rapidly and thus loses its mechanical strength. The test was carried out with a home-made device in accordance with ISO 4892-3 standard. The measured power of the UV chamber was $32.4 \mathrm{~W} / \mathrm{cm}^{2}$. The average solar energy in Hungary is $1368.6 \mathrm{kWh} / \mathrm{m}^{2}$ in a year ${ }^{[9]}$. The actual annual sunshine hours are 2057 hours / year. From these values, we determined that 1 hour irradiation of the UV chamber is approximately equal with 487 natural hour.

\subsection{Hardness Test}

The hardness value of the material is greatly influenced by the formed foam's structure. Because of the hardness of the material, we used a Zwick / Roell Shore D measuring instrument. The usage of the Shore D measurement is typically to measure harder plastics and composites.

\subsection{Tensile Test}

The tensile test measurement was carried out with an INSTRON 5566 instruments in accordance with ASTM D638-10 standard. The cross-head speed was $100 \mathrm{~mm} / \mathrm{min}$ and the measurement was carried out at room temperature.

\subsection{Impact Test}

For the impact test CEAST 6545 machine and 2J hammer were used. The EN ISO 179 standard was used to determine the properties of the plastics. 


\subsection{Three-Point Flexural Test}

Three-point bending test was used to determine the values of flexural strength and bending modulus according to ISO 178: 2010. We used an INSTRON 5566 Universal Material Testing Equipment for the tests.

\section{Results and Discussions}

\subsection{SEM}

The foam structure tests were carried out on the original and on the aged specimens. The first figure shows that the additive greatly ruined the formed foam structure. A more compact structure is formed where the fillers are largely located in the wall between the cells. Additionally, the miscibility problems are also displayed on the records. The corn cob accumulated in some areas of the structure, which modifies the mechanical properties. No significant structural changes were observed in Fig.2, Fig.3 shows a corn cob filler accumulation in the PVC structure. The SEM test can determine not only the structure, but also show the components. Table I and Table II. contain the test results of the marked areas 1 and 2 on Fig3.

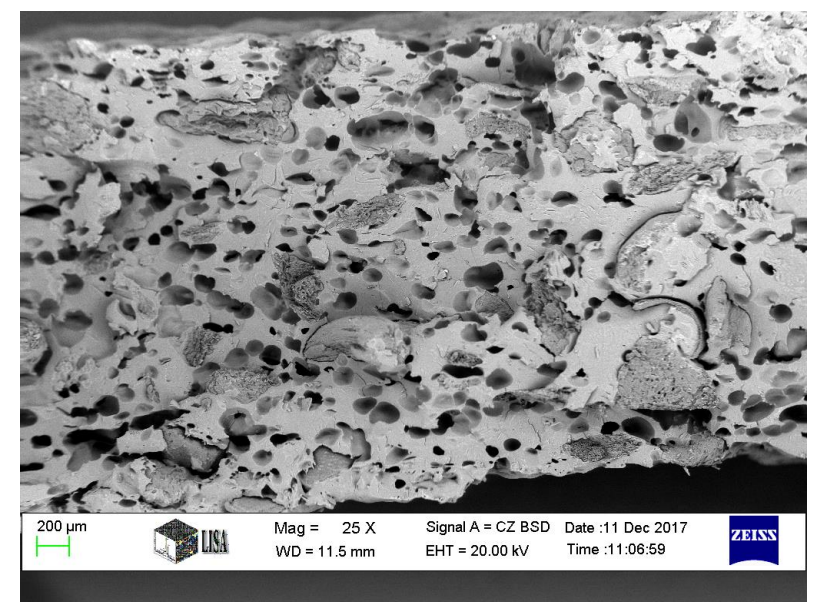

Figure 1: Before aging
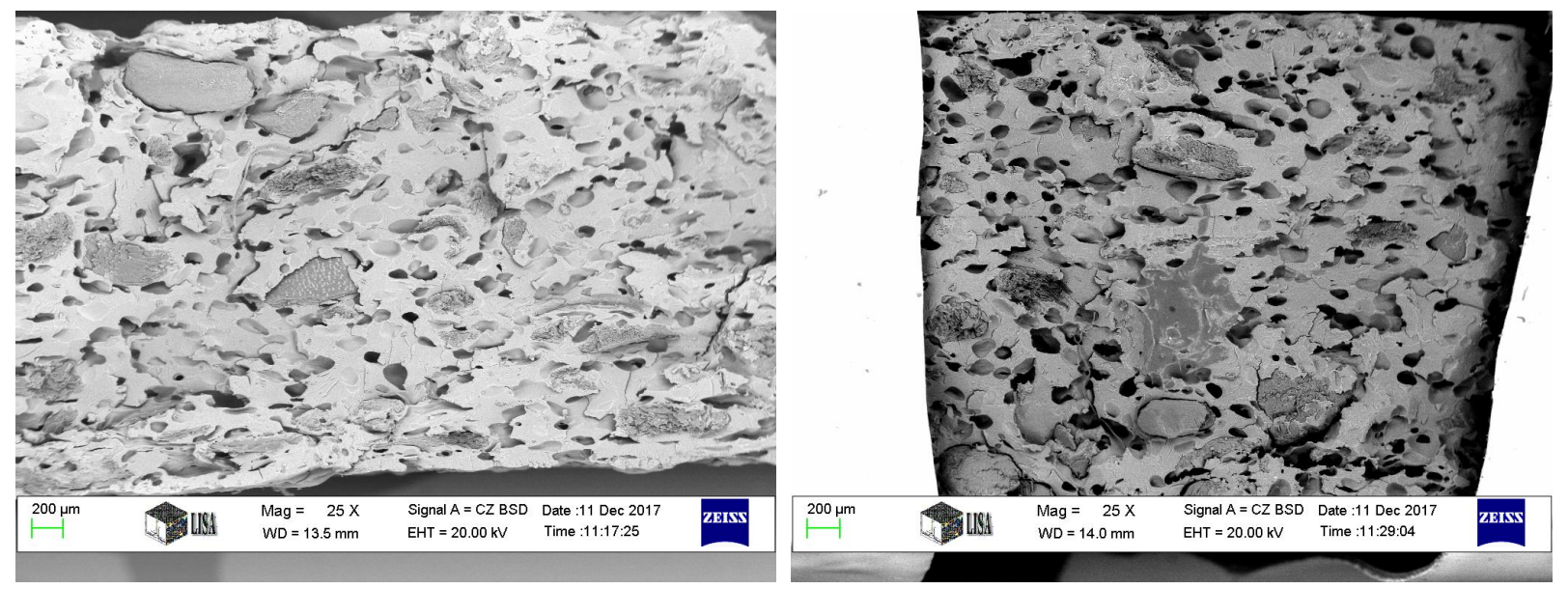

Figure 2: Equivalent 1 hour aging (left) and 3 hour aging (right) 


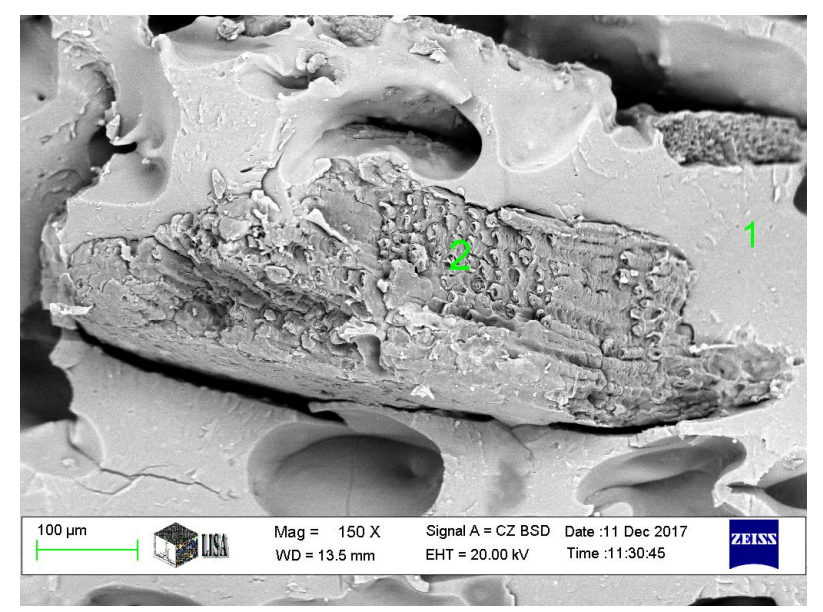

Figure 3: Equivalent 1 hour aging 150x scanning

Table 1: Result of 1 mark

\begin{tabular}{|l|l|}
\hline Element & Wt \% \\
\hline $\mathrm{C}$ & 43.73 \\
\hline $\mathrm{O}$ & 1.57 \\
\hline $\mathrm{Cl}$ & 54.71 \\
\hline
\end{tabular}

Table 2: Result of 2 mark

\begin{tabular}{|l|l|}
\hline Element & $\mathbf{W t} \%$ \\
\hline $\mathrm{C}$ & 62.99 \\
\hline $\mathrm{O}$ & 32.08 \\
\hline $\mathrm{Cl}$ & 4.94 \\
\hline
\end{tabular}

It can be seen from the results of Table I and II that the area 2 are indeed the corn cob filler, not an additive for any other processing.

\subsection{Hardness Test}

The SEM micrographs also support the results of hardness measurement. The corn cob strengthen the walls and rebuilds the entire structure, as a result, it increases its hardness value. The Shore D hardness of natural PVC foam is 38. It is interesting to note that often 1 hour aging the test specimen causes only a slight change in the hardness value. This is due to the degradation of the bonds in the structure and the oxidation. As a re result of further aging, the hardness value increases. As the hardness test causes minor deformation, this is obviously controversial with the tensile, impact and bending test. The results of the measurement are shown in Table III.

Table 3: Result of hardness test

\begin{tabular}{|l|l|l|l|}
\hline Samples & Before ageing & Equivalent to 1 years & Equivalent to 3 years \\
\hline PVC/Corn cob $66.14 \pm 1$ & $62.79 \pm 0.94$ & $63.2 \pm 0.72$ \\
\hline
\end{tabular}




\subsection{Tensile Test}

The results of the tensile tests demonstrate deterioration of the properties in the effect of aging. After 1 year aging no change in the structure was observed. Degradation caused by long time UV radiation has a detrimental effect in 3 years. The maximum tensile strength values of the tensile tests are shown in Table IV.

Table 4: Result of tensile test

\begin{tabular}{|l|l|l|l|}
\hline Samples & Before ageing & Equivalent to 1 years & Equivalent to 3 years \\
\hline $\mathrm{PVC} /$ Corn cob & $25.96 \pm 0.46$ & $25,04 \pm 0.97$ & $18.50 \pm 0.24$ \\
\hline
\end{tabular}

\subsection{Impact Test}

During the impact test, no significant change was observed in the strength value. In each case, the final strength values were determined from the average of 5 measurements.

Table 5: Result of Impact Test

\begin{tabular}{|l|l|l|l|}
\hline Samples & Before ageing & Equivalent to 1 years & Equivalent to 3 years \\
\hline PVC/Corn cob & $1.35 \pm 0.24$ & $1.09 \pm 0.13$ & $1.25 \pm 0.1$ \\
\hline
\end{tabular}

\subsection{Three-Point Flexural Test}

The results of the bending tests show an inverse tendency compared to the results of hardness measurements. The degradation of the structure in this case caused increasing flexural strength values of the 1-year specimens. Interestingly, the aged specimens have greater flexural strengths than the originals.

Table 6: Result of flexural strength

\begin{tabular}{|l|l|l|l|}
\hline Samples & Before ageing & Equivalent to 1 years & Equivalent to 3 years \\
\hline PVC/Corn cob & $34.62 \pm 0.94$ & $39.45 \pm 1.5$ & $37.76 \pm 1.7$ \\
\hline
\end{tabular}

Table 7: Result of flexural modulus

\begin{tabular}{|l|l|l|l|}
\hline Samples & Before ageing & Equivalent to 1 years & Equivalent to 3 years \\
\hline PVC/Corn cob & $1339.46 \pm 45.2$ & $1300.99 \pm 53$ & $1274.11 \pm 91$ \\
\hline
\end{tabular}

\section{Conclusions and Recommendations}

We have investigated the changes in the mechanical properties of PVC/Corn cob extruded foams due to aging. The foam specimens were aged in a UV chamber. The UV irradiation energy of the chamber was determined and compared with the intensity of natural sunlight in Hungary. The sets of the UV radiation times equal to the aging of 1 and 3 in nature years. SEM analysis and mechanical tests were performed on the original and aged specimens. Each mechanical measurement was performed five times. During the large deformation mechanical tests, degradation caused decreasing strength values of the material. In contrast, the values of the three- 
point bending tests have only slightly changed, i.e., the values have decreased over the 3 years old age. It can be assumed that some additives have been oxidized causing the hardening of the structure of the material. Accordingly, hardness values increased.

During the SEM analysis, the traces of aging do not show up in the internal structure, but in contrast, the additives in the structure could be determined. SEM images showed the wall thickening effect of the accumulated corn cob fillers.

\section{References}

[1] K. Roman, G. Zsoldos, Measurements of Rheological and Mechanical-,Thermo-mechanical properties of PVC/Corn cob foam composite, International Journal of Research-Granthaalayah, 5(10), 2017

[2] H. Jiand, D. Kamdem, Development of poly(vinyl chloride)/wood composites. A litrature review, 10 (2), 2004, 59-69

[3] W. Titow, PVC Technology 1984, 1047-1067

[4] A. Akinyemi, J. Afolayan, E. Ogunji Oluwatobi, Construction and Building Materials 127, 2016, 436-441

[5] B. Shah, L. Matuana, Online measurement of rheological properties of PVC/wood-flour composites, Journal of Vinyl and Additive Technology, 10 (3), 2004, 121-128

[6] George Wypych, PVC Degradation \& Stabilization, 3nd Edition, Toronto, 2015,186-198,

[7] M. Lanartowicz, B. Swinarew, A. Swinarew et al., The Evaluation of Long-Term Aged PVC, International Journal of Polymer Analysis and Characterization, 19 (7), 2014, 611-624

[8] Biocomposites from polypropylene and corn cob: Effect maleic anhydride grafted polypropylene, Advances in materials Research, 3 (3), 2014, 129-137

[9] 5 Milliárd nap mint nap!, http://5milliard.hu/eves-napsugarzasi-terkep-magyarorszagon/ (20.01.2018)

*Corresponding author.

E-mail address: polkrisz@ uni-miskolc.hu 